\title{
Contribuição Apresentada pela AN PEd nas Audiências Públicas sobre as "Diretrizes para a Formação Inicial de Professores da Educação Básica Em Curso de N ível Superior", Promovidas pelo Conselho Nacional de Educação*
}

\section{Iria Brzezinski}

Secretária Geral da ANPEd

Professora Titular da UCG

Pesquisadora Associada da UnB

\section{Primeiras considerações}

Venho à presença dos senhores Conselheiros, em nome da Presidente da Associação Nacional de PósGraduação e Pesquisa em Educação (ANPEd), Prof. ${ }^{a}$ Nilda Alves, a quem represento neste momento, reiterar meus cumprimentos ao Conselho Nacional de Educação (CNE) pela iniciativa de convidar diversas entidades da sociedade civil, para se pronunciarem, em audiência

* A ANPEd esteve presente em todas as audiências regionais realizadas para discutir a Proposta de diretrizes para a formação inicial de professores da educação básica, em cursos de nível superior, a saber: Porto Alegre, 19.03.2001, representada por Alfredo Veiga Netto, (Vice-Presidente); São Paulo, em 20.03.2001, representada por Elsa Garrido (Vice-Presidente); Goiânia, em 21.03.2001, representada por Iria Brzezinski (Secretária Geral); Recife, em 21.03.2001, representada por Janete Faria Lins de Azevedo; e Belém do Pará, em 23.03.2001, representada por Nilda Alves (Presidente). O texto acima contempla as intervenções feitas nas audiências regionais pelos diversos representantes e especificamente na audiência nacional, realizada em Brasília, em 12.04.2001, na qual a ANPEd foi representada por Iria Brzezinski (Secretária Geral). pública, sobre as Diretrizes Curriculares para a Formação de Professores para a Educação Básica.

A ANPEd, neste ano, comemora 25 anos de existência. Na verdade, ela foi institucionalizada como associação em 1978, porém a idéia de sua fundação remonta a 1976, logo, neste ano festeja-se seu jubileu de prata. Quero lembrar que a ANPEd constitui uma sociedade civil, que congrega programas de pós-graduação stricto sensu em Educação, professores e estudantes vinculados a estes programas e demais pesquisadores da área. Seu quadro social é composto por sócios, das seguintes categorias: sócios institucionais, que somam 51 Programas, e sócios individuais, que se reúnem em 19 Grupos de Trabalho (GT).

A identidade dos GT é consubstanciada, sobretudo, pelas pesquisas voltadas para temáticas educacionais específicas. Dos GT, cito o de "Formação de Professores", organizado em 1983, com a denominação "Licenciaturas" e que vem se dedicando, historicamente, aos estudos e pesquisas a respeito da formação de professores para a educação básica, embora essa questão interpenetre as temáticas de outros GT.

Lembro ainda que a Associação vem participando 
de diversos fóruns em que são discutidos os desdobramentos legais decorrentes da LDB - Lei n. 9394/96, entre eles as Diretrizes Curriculares.

A trajetória de pesquisa da ANPEd sobre a política de formação de professores e sua articulação com outras entidades, compartilhando princípios, permitiu não só acumular um acervo substantivo referente às propostas de diretrizes, mas também estabelecer amplos diálogos sobre o assunto, chegando a um pensamento comum.

Esse pensamento está registrado em um documento, do qual a ANPEd é signatária, que será apresentado ao CNE, nesta audiência, pelo Fórum Nacional em Defesa da Formação do Professor. ${ }^{1}$ Esse Fórum é o representante legítimo das associações científicas e sindicais que não se vergaram às arbitrariedades do Decreto n. 3.276/99, que "dispõe sobre a formação de professores para atuar na educação básica". As entidades que integram o Fórum engendraram uma luta nacional, a fim de assegurar a formação de professores em âmbito universitário. Com essa luta já se obteve algum êxito com o que preceitua o $\S 2^{\circ}$, do artigo $1^{\circ}$, do Decreto n. 3.554/ 2000 .

Diante de circunstâncias tão adversas das políticas educacionais do atual governo que investem contra a formação de professores na Universidade, garantida desde 1931 pelo Estatuto das Universidades Brasileiras, deve-se admitir que o Decreto n. 3.554/2000 "foi uma meia-vitória, mas foi uma vitória". ${ }^{2}$ Essa vitória se efetivou pela ação política imediata de denúncia feita pela sociedade civil organizada em entidades educacionais de representatividade democrática. A meia-vitória diz respeito da substituição do termo "exclusivamente" imposto pelo Decreto n. 3.276/99 por "preferencialmente". Tal como se apresentava, o texto legal constituía uma afronta à autonomia acadêmica da Universidade por designar somente aos Cursos Normais Superiores a formação de professores para atuação multidisciplinar, destinada ao magistério na educação infantil e nos anos iniciais do ensino fundamental.

Neste momento, gostaria de analisar o contexto

\footnotetext{
${ }^{1}$ Fórum (2001)

2 Expressão usada por Anísio Teixeira, cf. Lima (1974).
}

vivenciado pelos envolvidos na questão das diretrizes curriculares para a formação de professores da educação básica, em curso de nível superior. Negando a afirmação de Veyne (1982) de que "a história fala daquilo que jamais se verá duas vezes", vê-se nos dias atuais, por mais de duas vezes, a repetição de um fato histórico, porém agora marcado pelo ineditismo dos tempos, dos espaços e dos atores. Refiro-me ao fato que se repete continuamente no jogo das interações que se apresentam nas sociedades modernas, o da existência de dois mundos bem definidos: um mundo do sistema - o oficial - e outro, o vivido - o real. ${ }^{3}$

No processo de construção das diretrizes curriculares, a cisão entre esses mundos da sociedade brasileira mostra-se com muita nitidez. De um lado, o mundo do sistema que, aportado nas políticas de princípios neoliberais, saúda a globalização excludente como sinal inquestionável de progresso e de pós-modernidade, reafirmando parcerias com organismos internacionais. De outro, o mundo vivido, construído na luta travada desde 1980 pelo Movimento Nacional de Educadores, que propõe a adoção de uma política global de formação e de profissionalização docente. Essa política precisa considerar a Universidade como locus de formação inicial e promover a valorização do profissional da educação por mecanismos adequados de formação continuada, de melhoria das condições de trabalho, de uma carreira do magistério estimulante e de salários dignos.

A defesa da política global de formação e profissionalização do magistério pelo mundo vivido parte da concepção de que o professor é o profissional que domina o conhecimento específico de sua área e os saberes pedagógicos, em uma perspectiva de totalidade. Isso lhe permite perceber as relações existentes entre as atividades docentes e a globalidade das relações sociais, políticas e culturais em que o processo educacional ocorre e atuar como agente de transformação da realidade.

Com essa identidade, o professor é o profissional dotado das capacidades, entre tantas outras, de produzir conhecimento sobre seu trabalho, de tomar decisões em

\footnotetext{
3 Dicotomia inspirada em Teixeira (1962).
} 
favor da qualidade cognitiva das aprendizagens escolares e, fundamentalmente, de atuar no processo constitutivo da cidadania do "aprendente", ${ }^{4}$ seja ele criança, jovem ou adulto.

A identidade do professor como profissional do ensino, tal como foi definida, constrói-se como parte de um projeto de sociedade que se fundamenta na concepção histórico-social e tem como paradigma educacional as relações entre cultura, sociedade e educação. Esse paradigma leva em conta as transformações sociais, das forças produtivas e do mundo do trabalho, transformações que, dialeticamente, provocam mudanças no papel social do professor.

Diante da adoção desse paradigma, com o qual se busca a superação das desigualdades educacionais, a formação do profissional da educação para atuar na educação básica é entendida como um processo marcado pela complexidade do conhecimento, pela crítica, pela reflexão-ação e pela criatividade.

O mundo oficial, por sua vez, diante da dependência para com os organismos estrangeiros, financiadores das políticas educacionais brasileiras, submete-se ao modelo de formação de profissionais da educação implantado em outros países. Esse modelo institucionaliza preferencialmente a formação fora da Universidade e preocupa-se muito mais em conceder uma certificação do que conferir uma boa qualificação aos futuros professores do sistema educacional e aos leigos que nele atuam.

Decorrente desse modelo, o preparo do professor centra-se no desenvolvimento de competências para o exercício técnico-profissional, consistindo, pois, em uma formação prática, simplista e prescritiva, baseada no saber fazer para o aprendizado do que vai ensinar. Infelizmente esta é a concepção de formação de professores predominante no documento do CNE sobre as diretrizes curriculares para a formação inicial de formação de professores da educação básica em nível superior.

4 Termo utilizado por Shulman (1986) para designar aquele "ser que aprende" como autor de sua própria aprendizagem, em um trabalho coletivo e participado. Neste sentido, esse conceito é diferente do significado dado tanto ao estudante que se isola para estudar como ao atribuído ao aluno (do grego - sem luz) que ouve passivamente preleções nas aulas.
É preciso mencionar que alguns atores, hoje atuantes no mundo oficial, até há pouco representantes do mundo vivido e esperança dos educadores para a transformação desse modelo de formação imposto, surpreendentemente, neste processo de construção das diretrizes curriculares, postaram-se do lado do mundo oficial.

Quero acreditar que, atualmente, vive-se um processo de mudanças e com certas aproximações entre o mundo oficial e o real. Quero acreditar, também, que as várias audiências regionais e esta audiência nacional sobre diretrizes curriculares estão sendo realizadas justamente com o intuito de acatar as sugestões advindas do mundo real e não para dissimular práticas, a fim de legitimar decisões previamente acordadas com os "mandatários" do sistema e que vão ao encontro dos interesses dos educadores. ${ }^{5}$

Esclareço que o mundo vivido, do qual tenho a honra de representar uma pequena parcela, não se coloca em uma radical posição maniqueísta, segundo a qual tudo o que vem do mundo oficial é totalmente negativo. Ao contrário, o Movimento Nacional de Educadores reconhece que o modelo atual de formação feita na Universidade precisa ser redimensionado para corresponder às exigências da sociedade do conhecimento e do alicerce do sistema educacional - a educação básica. O mundo real reconhece também a importância da diversidade de locus de formação de professores em nosso país de muitos "brasis"; adverte, porém, que reconhece essa diversidade como solução transitória, com tempo de duração definido e avaliada institucional e externamente.

O que o mundo vivido não pode aceitar é a multiplicidade de locus e de modalidades de formação propostas pelo sistema, acopladas à defesa da livre iniciativa, que poderá instalar qualquer tipo de instituição e cursos presenciais e a distância, sem que, por um lado, se assegure a necessária qualidade de ensino e, por outro, estabeleça-se como horizonte, em um futuro próximo, um único ponto de chegada: a formação inicial de profissionais da educação na Universidade.

Gostaria, neste momento, de destacar que houve um esforço da Comissão Bicameral do CNE para fazer al-

5 Ver ANPEd. Carta de Caxambu: Ao povo brasileiro e às autoridades constituídas, publicado nesta mesma seção. 
terações na Versão Preliminar da Proposta de Diretrizes (MEC/CNE, fev. 2001), dando mostras de sua sensibilidade para com as contribuições oferecidas pelo mundo real durante as audiências públicas regionais realizadas em março de 2001, no tocante às questões polêmicas e não consensuais, contidas na proposta de diretrizes curriculares do mundo oficial.

Mesmo assim, julgo necessário retornar a alguns pontos polêmicos, porque ainda estão presentes na última versão (MEC/CNE, abr. 2001). Peço desculpas por tornar o assunto repetitivo, uma vez que muitos pontos já foram destacados pela ANPEd nas citadas audiências regionais e reafirmados também no documento aqui referido, a ser apresentado pelo Fórum Nacional em Defesa da Formação do Professor, porta-voz do pensamento comum das associações e entidades do mundo vivido.

\section{Pontos polêmicos}

\section{Concepção de pesquisa}

Reconheço que a última versão das Diretrizes Curriculares modificou em parte a enviesada concepção de pesquisa quando retirou do texto anterior "que a pesquisa (ou investigação) que se desenvolve no âmbito do trabalho do professor não pode ser confundida com a pesquisa acadêmica ou científica"(MEC/CNE, fev. 2001, p. 35). Porém, o grande equívoco suscitado por essa afirmação constante da versão preliminar requer que seja melhor explicitada a nova concepção de pesquisa expressa nas páginas 35 a 37 da versão em vigor.

Com o propósito de contribuir com a necessária reflexão sobre a concepção de pesquisa retomo alguns questionamentos já feitos pela ANPEd. Volto, então, a perguntar: Existe pesquisa não-científica? Estariam os elaboradores do documento tão impregnados da concepção prática do saber-fazer que desconsideram quão científica é a investigação sobre o cotidiano da realidade escolar? Estariam, então, negando o caráter científico da pesquisa-ação, da pesquisa participante, da investigação sobre o fazer pedagógico? Desse modo, os elaboradores desqualificam a pesquisa como princípio formativo e cognitivo da docência e se descuidam do vínculo da investigação com os demais componentes do ato educativo.
Ao desqualificar a pesquisa como princípio formativo da docência, a proposta de diretrizes curriculares desvincula a pesquisa do ensino e não leva em conta um compromisso histórico, assumido pela Universidade para a formação de professores, que é o de incentivar a pesquisa desde a graduação, com a iniciação científica, até a pós-graduação stricto sensu. Conseqüentemente, a proposta de diretrizes curriculares deixa explícito que a formação de professores deve ser técnico-profissionalizante e, sendo assim, distancia-se do entendimento de que o professor deve ser um profissional culto, crítico e comprometido com a construção do saber. Fica claro que a lógica da proposta é a do aligeiramento e da simplificação com visível "economia" de conteúdos essenciais para a formação do magistério.

\section{O rganização institucional das escolas de formação inicial}

Saliento o substantivo avanço, na última versão das Diretrizes, quando os elaboradores da proposta apresentam uma nova redação e advogam que: a) a formação de professores deve ser realizada como um processo autônomo, em curso de licenciatura plena, numa estrutura com identidade própria; b) os cursos de formação de professores devem manter estreita parceria com institutos, departamentos e cursos de áreas específicas (p. 50).

Essa nova redação eliminou da versão preliminar o que aparece destacado a seguir "a formação de professores deve ser realizada como um processo autônomo, numa estrutura com identidade própria, distinta dos cursos de bacharelado e dos programas ou cursos de formação de especialistas em educação e mantendo estreita parceria entre institutos, departamentos e cursos de áreas específicas" (p. 45).

Na opinião da ANPEd, a nova versão ultrapassa a concepção existente na versão preliminar de uma escola de formação de professores que apontava para uma ruptura entre o local de formação e o local onde também se constrói conhecimento sobre cada área específica do currículo da escola básica - o bacharelado. A garantia desse forte vínculo orgânico - entre onde se processa a formação de professores e onde também se produz conhecimento sobre as especificidades - deverá favorecer o intercâmbio entre os saberes próprios de cada campo 
de conhecimento e promover a tão almejada interdisciplinaridade entre os conteúdos disciplinares e os saberes pedagógicos.

Enfatizo ainda que a nova versão, deixando de separar os cursos que formam professores dos que formam "especialistas" da educação, passa a reconhecer a trajetória do Movimento Nacional de Educadores que defende a docência como a base da identidade da formação dos profissionais da educação, ou seja, que todo profissional da educação é um professor.

A base comum nacional necessária à formação docente, sustentada por esse Movimento, possibilita uma formação teórica sólida, bem como a apropriação do conhecimento sobre o campo de trabalho onde o profissional deverá atuar, a escola. Desse modo, tal formação oferece condições para que o professor que domina a base comum nacional como base docente busque as mais diferentes especializações como forma de aperfeiçoar seu preparo, tanto na formação inicial como na continuada.

Muitos, então, são os avanços. Todavia, na contramão da história que vem sendo escrita na luta dos educadores pela valorização dos profissionais da educação, a última versão da proposta das Diretrizes não reconhece que as Faculdades de Educação, com o Curso de Pedagogia atualmente ressignificado, já têm dado mostras de que constituem locus próprio para formar o professor da educação infantil e o professor multidisciplinar para atuar nas séries iniciais do ensino fundamental. No entendimento do Movimento Nacional de Educadores, partilhado pela Comissão de Especialistas da Pedagogia da SESU/MEC, essa é a organização institucional, já existente, adequada à formação necessária e comprovada pelos 458 cursos no país, ${ }^{6}$ que formam o pedagogo, que têm como base a docência no preparo do profissional para atuar na educação infantil e nas séries iniciais do ensino fundamental.

A proposta de Diretrizes curriculares, na versão de fevereiro de 2001, revelava desprezo para com o curso de Pedagogia, pois sequer o citava como lugar de formação do professor da educação infantil e do professor multidisciplinar do ensino fundamental na instituição

6 Dado apresentado por Merion Bordaz (2001), membro da Comissão de Especialistas em Pedagogia. universitária. O documento apenas sinalizava que a Universidade e os Centros Universitários poderiam formar esses professores em "outros cursos" que, necessariamente, não precisavam se denominar Curso Normal Superior, curso que a proposta de Diretrizes destina à formar professores da educação infantil e das séries iniciais no contexto dos Institutos Superiores de Educação (ISE). Em nenhum instante propunha que profissionais do ensino pudessem ser formados no curso de Pedagogia.

A versão atual passou a reconhecer a existência do curso de Pedagogia quando, ao se reportar a alguns pontos dignos de nota no Decreto n. 3.276/99, alterado pelo Decreto n. 3.554/2000, propõe "a manutenção, no caso das Universidades e de Centros Universitários, dada sua autonomia, da alternativa de que a formação de professores se processe em cursos com outra denominação, como os de Pedagogia, desde que observadas estas Diretrizes" (p. 16).

Apesar desse reconhecimento, o mundo vivido julga que ainda é indispensável avançar no que concerne à organização institucional e curricular da formação inicial de profissionais para a educação básica, visando diminuir os dissensos e solicita:

a) a recomendação explícita da adoção da base comum nacional, com enfoque na docência, para todos os cursos que formam profissionais para a Educação, para que se garanta unidade para a multiplicidade de experiências curriculares, sem as limitações de um currículo mínimo e sem prejuízo do reconhecimento das instituições de ensino superior e dos currículos dos estudantes;

b) a explicitação de que as diretrizes nacionais sobre formação do professor para educação básica são aplicáveis à formação de professores que ocorre no curso de Pedagogia;

c) o estabelecimento de diretrizes específicas para o curso de Pedagogia, como licenciatura plena, com base na proposta da Comissão de Especialistas em Pedagogia, de 06.06.1999;

d) a indicação de diretrizes curriculares específicas para a formação de formadores, isto é, para formação de professores do ensino superior que formam professores; 
e) o fortalecimento da concepção de que os cursos de formação de professores são cursos de licenciatura plena, com duração mínima de 3.200 horas e não habilitações de outros cursos agregados a outra graduação;

f) a eliminação da licenciatura de curtíssima duração em nível superior, com 1.600 horas, legalizada pela dispensa para os futuros professores não só de 800 horas pela prática anterior, mas também de 800 horas para aqueles que foram habilitados em cursos de Magistério, em nível médio. Na opinião da ANPEd, o aproveitamento de 800 horas da "prática anterior" como cumprimento da prática de ensino exigida pela LDB para todos os cursos que formam professores para a Educação Básica (art. 65) surge na proposta de diretrizes curriculares como um mecanismo que poderá dissociar na formação do professor o que, pela natureza conceitual, é indissociável: a teoria da prática;

g) a aplicação dos mesmos requisitos mínimos exigidos para a formação de professores feita no âmbito universitário para as instituições não universitárias, enquanto a realidade de muitos "brasis" necessitar dessas instituições, mas que elas sejam consideradas como locais transitórios e não permanentes de formação;

h) estabelecimento de rigorosos mecanismos de avaliação externa e de auto-avaliação de todas as instituições e modalidades de formação presencias e não presenciais, a fim de impedir as formas aligeiradas de certificação de professores;

i) a definição de políticas educacionais e destinação de recursos de tal ordem que a formação inicial de todos os profissionais da educação seja feita na universidade, preferencialmente pública.

\section{Caráter iminentemente prático emprestado ao modelo de formação de professores.}

A maior expressão desse caráter está na concepção de competência adotada, que enfatiza o fazer na prática pedagógica. Como está definida na proposta, competência se restringe a um saber prático que vai se consolidando na situação de ensino e na vivência de problemas cotidianos, como objeto das pesquisas para solucionar problemas práticos e imediatos.

Além de conferir ao trabalho do professor um caráter muito próximo ao artesanal, a proposta focaliza o ensino, especialmente, na aprendizagem, com um forte destaque para a prática, o que se contrapõe à idéia de formação que se fundamenta na produção de conhecimento teórico, mediante a inserção em realidades concretas.

Neste sentido, o mundo vivido solicita: a ressignificação do conceito de competência para ultrapassar o caráter reducionista de um saber prático, assegurando a indissociabilidade da teoria e a prática nesse conceito, ou seja, garantindo o entendimento de que a competência é centrada na práxis.

\section{Finalizando}

Para finalizar, destaco o profundo significado do diálogo que audiências públicas, como esta, permitem que se estabeleça entre o CNE e os representantes da sociedade civil interessados na questão educacional. A ANPEd mantém-se comprometida com a participação e se coloca à disposição do CNE, neste momento decisório, para eticamente firmar uma parceria entre o mundo vivido e o mundo oficial, com o intuito de que sejam atendidas as solicitações aqui feitas em relação às diretrizes curriculares para a formação de profissionais da educação básica.

O desafio que impulsiona tal parceria fundamentase na certeza de que a composição entre contrários resulta uma reflexão mais profunda acerca da verdade e de que, como afirmou Henfil, "não é o desafio com que nos deparamos que determina quem somos e o que estamos nos tornando, mas a maneira como respondemos ao desafio".

\section{Referências bibliográficas}

BRASIL. PODER EXECUTIVO, (1932). Decreto n. 19.851, de 11.04.1931, do chefe do Governo Provisório da República dos Estados Unidos do Brasil. Dispõe que o ensino superior do Brasil obedecerá, de preferência, ao systema universitário. Lei da Repú- 
blica dos Estados Unidos do Brasil observados os dispositivos do Estatuto das Universidades Brasileiras. In: Coleção das Leis da República dos Estados Unidos do Brasil de 1931. Atos do Governo Provisório. Rio de Janeiro: Imprensa Nacional, v.1.

(1967). Lei 4.024, de 20.12.1961. Fixa diretrizes e bases da educação nacional. In: Nóbrega, V. Enciclopédia da legislação do ensino. São Paulo: Empresa Gráfica da Revista dos Tribunais, p. 17-40.

(1996). PR. Lei 9.394, de 20.12.1996. Estabelece as diretrizes e bases da educação nacional. Diário Oficial da União. Brasília: Gráfica do Senado, a. CXXXIV, n. 248, 23.12.1996, p. $27833-27841$.

(1999). Decreto n. 3.276, de 06.12.1999. Dispõe sobre a formação de professores em nível superior para atuar na educação básica, e dá outras providências. Diário Oficial da União. Brasília: Gráfica do Senado, 07.12.1999.

, (2001). Decreto n. 3.554, de 07.08.2000. Dá nova redação ao $\S 2$ o do art. $3^{\circ}$ do Decreto n. 3.276, de 06.12.1999. In: Parecer CNE/CES n. 133/2001, de 30.01.2001.

, (2001). MEC/CNE. Proposta de diretrizes para a formação inicial de professores da educação básica, em cursos de nível superior. Versão preliminar. Brasília, (mimeo).

, (2001). MEC/CNE. Proposta de diretrizes para a formação inicial de professores da educação básica, em cursos de nível superior. Última versão. Brasília, 20.04.2001. www.gov.mec/cne.

, (2000). A ANPEd na comissão geral da Câmara dos Deputados. Boletim ANPEd, n. 02, Rio de Janeiro, ago., p. 2.

, (2001). Contribuição à Audiência Pública Regional Centro-Oeste sobre "Diretrizes para a Formação Inicial de Professores da Educação Básica em curso de Nível Superior”, realizada em Goiânia, 21.03.2001. www.mec.gov/cne.

\section{FÓRUM NACIONAL EM DEFESA DA FORMAÇÃO DO PROFES-} SOR, (2001). Contribuições das entidades ANPEd, Anfope, Anpae, Forundir e Fórum Nacional em Defesa da Formação Do Professor para subsidiar discussão na audiência pública nacional/CNE sobre a formação do professor para educação básica em cursos de nível superior, de 23.04.2001. Brasília (mimeo).

LIMA, L. de O., (1974). Estórias da educação no Brasil: de Pombal a Passarinho. Rio de Janeiro: Editora Brasília.

SHULMAN, L., (1986). Those who understand: knowledge growth in teaching. Educacional Reserch, v.15, n. 2, p. 4-14.

TEIXEIRA, A., (1962). Valores proclamados e valores reais das instituições escolares brasileiras. Revista Brasileira de Estudos Pedagógicos, v. 37, n. 86, Rio de Janeiro: MEC/INEP, abr./jun., p. 59-79.

VEYNE, P., (1982). Como se escreve a história. Foucault revoluciona a história. Brasília: Editora UnB. 